\section{Postdocs need a career structure}

SIR-The recent letter (Nature 325, 478; 1987) from D. J. Murphy, who suggests removing age-related postdoc salary scales in British universities, offers a shallow solution to a grave problem, and begs the question of what level the postdoc salary would be set at. We presume, as the aim of such an exercise is to allow older postdocs to compete with their younger counterparts, that they are deemed to be worth less than their current salaries, and not that younger postdocs are underpaid. But reducing the salary of all postdocs to the $£ 8,000-£ 9,000$ level would mean that some older postdocs would be paid less than the technical staff with whom they work.

Murphy says this solution might not entirely halt the increasing drain of talent away from Britain. We suggest it would most certainly increase the drain. Not only that, it would drive many talented scientists out of science altogether.

Murphy also fails to appreciate that many older postdocs find themselves in their present position not by choice but simply because there is minimal recruitment of lecturers and government research scientists. Older postdocs do not want to be postdocs for the rest of their lives, to act as "assistants" (Nature 326, 122: 1987) to older scientists who are fortunate enough to be tenured. They are certainly not prepared to do this for the level of salary Murphy envisages.

Older postdocs are certainly a "formidable pool of talent for the nation" but let us not devise schemes to further exploit them. The "obvious solution" is to provide them with employment as independent scientists and hence permit realization of their worth.

\section{J.R. SPEAKMAN G.R. IASON M.S. GRISLEY}

University of Aberdeen, Department of Zoology, Aberdeen AB9 2TN, UK

SiR-P. N. Campbell (Nature 326, 122; 1987) highlights the plight of postdoctoral research assistants. In response to an advertisement for a research fellowship at a northern technological university, I was appointed as a research assistant as I had yet to complete my PhD. I had no argument with this decision. Much to the embarrassment of my professor, however, the university refused to promote me to research fellow upon completion of my $\mathrm{PhD}$, appointing me instead to postdoctoral research assistant. I then had to reapply for my own job (and be reinterviewed by four senior academics) before being appointed as a research fellow. During the interview, my professor refused to ask me any questions, as he con- sidered university administrators and outmoded regulations were to blame for the situation. If universities can be responsible for such time-wasting farces, then it is no wonder the government is scrutinizing their activities.

\section{Bowmans Avenue, Hitchin,} Hertfordshire $S G 49 Q D, U K$

\section{First things first}

SIR-The question of whether authors should use the word 'first' to imply a priority research finding has received considercourse demanding for a referee or editor to be vigilant and review the associated literature to ensure that such statements are warranted, should editorial policy permit them. However, it was surprising to read in Nature of the "first experimental data for prokaryotic regulation at distances $>1 \mathrm{~kb}^{\text {"3 }}$ when in a recent review published in Nature references to work $^{5}$ which could have drawn the same priority statement were made, as indeed might have a letter published last March ${ }^{6}$. Perhaps Nature should adopt the same policy ${ }^{2}$ as Proceedings of the National Academy of Sciences of the USA with respect to priority statements to protect not only the authors but the journal also.

Martin Buck

RAY DIXON

Martin Drummond

ARC Unit of Nitrogen Fixation,

University of Sussex,

Brighton BN1 9RQ, UK

Maddox, J. Nature 324, 509 (1986)

Zwanzig, F.R. Nature 325, 754 (1987)

Dandanell, G. et al. Nature 325, 823 (1987)

Ptashne, M. Nature 322, 697 (1986)

Reitzer, L J \& Magasanik, B. Cell 45, 785 (1986)

6. Buck, M et al Nature 320, 374 (1986)

\section{Fundamental split}

SiR-The recent reports in Nature concerning the steady decline in the quality and quantity of British science and the lack of cohesion between fundamental and applied research have been illuminating but have often lacked concrete examples of political and professional decisions that will have an adverse effect on an important area of science in which Britain currently has a toe-hold. The recent decisions to sell the breeding programmes at the Plant Breeding Institute (PBI) and to relocate the remaining public sector scientists at the John Innes Institute and Rothamsted Experimental Station are clear examples of political shortsightedness that will critically weaken an important sector of British science.

The immediate effect of these decisions will be to drive skilled researchers who able comment in Nature recently ${ }^{1,2}$. It is of wish to work in a secure environment from the Agricultural and Food Research Council (AFRC).

Second, the decisions will separate the disciplines of molecular biology and plant breeding which many of us at the PBI have been striving to join. The benefits of these collaborations have become apparent recently in planned field trials of genetically engineered potatoes and the use of DNA probes in breeding programmes, and it is generally believed that the application of these methods of molecular biology will have a profound effect on plant breeding and agriculture. Indeed, many chemical companies interested in genetic engineering have purchased seed companies to obtain breeding teams. It will take many years to recreate the special interaction between breeder and molecular biologist that exists at the PBI; in fact we do not know if the AFRC intends to continue this work. Given the parlous state of the economy, I doubt if extra money will be provided for breeding programmes at the John Innes and Rothamsted.

Finally, moving the molecular biology activities of the $\mathrm{PBI}$ from Cambridge will remove the stimulating day-to-day contact we have with biologists at the university and the Laboratory of Molecular Biology. It may also prove more difficult to attract visiting scientists who are at present drawn by the special scientific atmosphere of Cambridge.

Plant Breeding Institute,

Maris Lane,

Cambridge CB2 2LQ, UK

\section{Colonizing space}

SIR-Robert Shepherd's letter on the colonization of space (Nature 326, 124; 1987) misses an important point. It is true that an attempt to colonize the other planets in the Solar System while they are in their present state would probably be unproductive, but it may be possible to change their environments (at least for Mars and Venus) so that they become habitable ${ }^{1-3}$. Moreover, it seems rather unlikely that extra-solar planets will have environments that are perfectly suitable for human habitation, and colonization may require that their original environments be changed. Such a procedure would greatly increase the number of habitable planets in the Galaxy, and experience gained in our own Solar System would be invaluable.

IAN CRAWFORD

University of London Observatory

Annexe and Planetary Image Centre,

33-35 Daws Lane,

London NW7 4SD, UK

1. Zwicky, F. Observatory 68, 121 (1948)

Sagan, C. Science 133, 849 (1961)

Allaby, M. \& Lovelock. J. The Greening of Mars (Deutsch, London, 1984) 